\title{
Effects of Ibuprofen Use on Lymphocyte Count and Oxidative Stress in Elite Paralympic Powerlifting
}

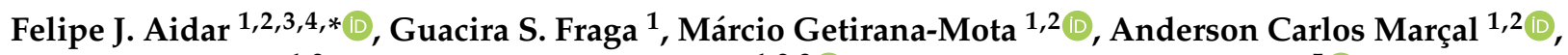 \\ Jymmys L. Santos ${ }^{1,2}$, Raphael Fabricio de Souza ${ }^{1,2,3} \mathbb{D}^{\mathbb{D}}$, Alexandre Reis Pires Ferreira ${ }^{5} \mathbb{D}^{\circ}$, Eduardo Borba Neves ${ }^{6}{ }^{\circ}$, \\ Aristela de Freitas Zanona ${ }^{7}$, Alexandre Bulhões-Correia ${ }^{8}{ }^{\circ}$, Paulo Francisco de Almeida-Neto ${ }^{8} \mathbb{C}$, \\ Tulio Luiz Banja Fernandes ${ }^{9}$, Nuno Domingos Garrido ${ }^{10}{ }^{0}$, Maria do Socorro Cirilo-Sousa ${ }^{11,12}$, \\ María Merino-Fernández ${ }^{13}$, Alfonso López Díaz-de-Durana ${ }^{14}$, Eugenia Murawska-Ciałowicz ${ }^{15}$ (D), \\ Breno Guilherme de Araújo Tinoco Cabral ${ }^{8}$ (i) and Filipe Manuel Clemente ${ }^{16,17}$ (])
}

Citation: Aidar, F.J.; Fraga, G.S.; Getirana-Mota, M.; Marçal, A.C.; Santos, J.L.; de Souza, R.F.; Ferreira, A.R.P.; Neves, E.B.; Zanona, A.d.F.; Bulhões-Correia, A.; et al. Effects of Ibuprofen Use on Lymphocyte Count and Oxidative Stress in Elite Paralympic Powerlifting. Biology 2021, 10, 986. https://doi.org/10.3390/ biology10100986

Academic Editors: Redha Taiar and Anne Delextrat

Received: 16 July 2021

Accepted: 23 September 2021

Published: 30 September 2021

Publisher's Note: MDPI stays neutral with regard to jurisdictional claims in published maps and institutional affiliations.

Copyright: (c) 2021 by the authors. Licensee MDPI, Basel, Switzerland. This article is an open access article distributed under the terms and conditions of the Creative Commons Attribution (CC BY) license (https:/ / creativecommons.org/licenses/by/ $4.0 /$ )
1 Graduate Program of Physical Education, Federal University of Sergipe (UFS), São Cristovão 49100-000, Brazil; guacirafraga@yahoo.com.br (G.S.F.); marcio_getirana@hotmail.com (M.G.-M.); acmarcal@yahoo.com.br (A.C.M.); jymmys.lopes@gmail.com (J.L.S.); raphaelctba20@hotmail.com (R.F.d.S.)

2 Group of Studies and Research of Performance, Sport, Health and Paralympic Sports (GEPEPS), Federal University of Sergipe (UFS), São Cristovão 49100-000, Brazil

3 Department of Physical Education, Federal University of Sergipe (UFS), São Cristovão 49100-000, Brazil

4 Graduate Program of Physiological Science, Federal University of Sergipe (UFS), São Cristovão 49100-000, Brazil

5 College of Physical Education and Exercise Science, University of Brasília (UnB), Brasília 70910-900, Brazil; alexandreispf@gmail.com

6 Graduate Program in Biomedical Engineering, Federal Technological University of Paraná (UTFPR), Curitiba 80230-901, Brazil; eduardoneves@utfpr.edu.br

7 Department of Occupational Therapy, Federal University of Sergipe (UFS), Lagarto 49400-000, Brazil; arisz_to@yahoo.com.br

8 Department of Physical Education, Federal University of Rio Grande do Norte, Natal 59064-741, Brazil; alexandrebulhoescorreia@gmail.com (A.B.-C.); paulo220911@hotmail.com (P.F.d.A.-N.); brenotcabral@gmail.com (B.G.d.A.T.C.)

9 Institute of Physical Education and Sport, Federal University of Ceará (UFC), Fortaleza 60020-181, Brazil; banja@ufc.br

10 Research Center in Sports Sciences, Health Sciences and Human Development (CIDESD), University of Trás-os-Montes e Alto Douro, 5001-801 Vila Real, Portugal; ngarrido@utad.pt

11 Graduate Program Association of Physical Education, Federal University of Paraíba (UFPB), João Pessoa 58051-900, Brazil; helpcirilo@yahoo.com.br

12 Department of Physical Education, Regional of University (URCA), Crato 63105-010, Brazil

13 Faculty of Health Sciences, Universidad Francisco de Vitoria (UFV), 28223 Madrid, Spain; m.merino.prof@ufv.es

14 Sports Department, Physical Activity and Sports Faculty-INEF, Universidad Politécnica de Madrid, 28040 Madrid, Spain; alfonso.lopez@upm.es

15 Physiology and Biochemistry Department, University School of Physical Education, 51-612 Wroclaw, Poland; eugenia.murawska-cialowicz@awf.wroc.pl

16 Escola Superior Desporto e Lazer, Instituto Politécnico de Viana do Castelo, Rua Escola Industrial e Comercial de Nun'Álvares, 4900-347 Viana do Castelo, Portugal; filipe.clemente5@gmail.com

17 Instituto de Telecomunicações, Delegação da Covilhã, 1049-001 Lisboa, Portugal

* Correspondence: fjaidar@gmail.com; Tel.: +55-(79)-99685-7777

Simple Summary: Paralympic Powerlifting (PP) is a strength sport and training tends to promote fatigue. Ten national-level PP athletes were evaluated concerning post-training oxidative stress using Ibuprofen and a placebo. Strength indicators were evaluated. The training consisted of five sets of five repetitions (80-90\% 1-Repetition Maximum) in the bench press. The IBU had a positive effect on strength indicators, with decreased fatigue and increased lymphocyte count. There were no differences in oxidative stress. The use of IBU provided improvements in strength and fatigue reduction and did not protect against oxidative stress.

Abstract: Background: Paralympic Powerlifting (PP) training tends to promote fatigue and oxidative stress. Objective: To analyze the effects of ibuprofen use on performance and oxidative stress in posttraining PP athletes. Methodology: Ten national level PP athletes (age: $27.13 \pm 5.57$ ) were analyzed 
for oxidative stress in post-training. The study was carried out in three weeks, (1) familiarization and ( 2 and 3 ) evaluated the recovery with the use of a placebo (PLA) and ibuprofen (IBU), $800 \mathrm{mg}$. The Peak Torque (PT), Torque Development Rate (TDR), Fatigue Index (FI), reactive substances to thiobarbituric acid (TBARS) and sulfhydryl groups (SH) were evaluated. The training consisted of five sets of five repetitions (80-90\%) 1-Repetition Maximum (1-RM) in the bench press. Results: The IBU showed a higher PT (24 and $\left.48 \mathrm{~h}, p=0.04, \mathrm{\eta}^{2} p=0.39\right)$, a lower FI ( $\left.24 \mathrm{~h}, p=0.01, \mathrm{n}^{2} p=0.74\right)$ and an increased lymphocyte count $\left(p<0.001 ; \eta^{2} p=4.36\right)$. There was no change in oxidative stress. Conclusions: The use of IBU provided improvements in strength and did not protect against oxidative stress.

Keywords: Paralympic Powerlifting; ibuprofen; muscle strength; oxidative stress; recovery of function

\section{Introduction}

Paralympic Powerlifting is characterized by being a sport that demands high intensities during competitions and training, and the training demands progressive overloads to take athletes to the peak of the required physical performance [1,2]. Due to training overloads, it is necessary to perform an adequate recovery so that athletes have performance gains. When insufficient recovery occurs, tissue injury may be induced and may lead athletes to overtrain (loss of performance due to the accumulation of training shifts without adequate recovery) $[1,3]$.

It is noteworthy that intense physical exercise is a physiological stress capable of altering immune responses and blood biomarkers [4]. Scientific studies show that intense physical exercise can modulate the leukocyte count in the bloodstream and the interaction of these leukocytes (neutrophils and monocytes/macrophages) with endothelial cells in the muscle and consequent transmigration to the damaged skeletal muscle tissue $[5,6]$.

Physical exercise, immune system and oxidative stress indicate that volume and intensity are directly related to alterations in the redox balance, and the excessive increase in production or the reduction of antioxidant capacity, which can induce oxidative damage to lipids, proteins and nucleic acids [7,8]. Excessive loads of physical exercise can generate oxidative stress, considering that physical exercise can promote the formation of ROSs (i.e., reactive oxygen species) in the human body $[9,10]$. It is noteworthy that ROSs can cause tissue damage and, in high concentrations, damage cellular organelles, nucleic acids, lipids and proteins, causing harm to human health [6]. In the same direction, it has been reported that strenuous exercise, as in strength training, tends to increase stress biomarkers. Thus, oxidative stress has been associated with strength training [11-13]. Exercise-induced oxidative stress has been associated with reactive oxygen species (ROSs), especially during exercise [14], as well as post-intensive exercise muscle damage and inflammation that tend to contribute to increased oxidative stress [12,15]. In this sense, it has been suggested that elite powerlifters may benefit from blunted responses to oxidative stress after intensive weightlifting sessions, which may have implications for recovery between training sessions (Ammar et al., 2017a). Therefore, to reduce oxidative stress and protect athletes' bodies with the objective of enhancing the recovery process, many methods have been proposed and used, among which ibuprofen (IBU), which is a non-steroidal anti-inflammatory drug (NSAID), stands out for self-administrative use $[1,16]$. However, the use of NSAIDs can inhibit the muscle myofibers regeneration, the proliferation and the differentiation of satellite cells, and muscle hypertrophy induced by an adaptation to training overload [17-19].

For this reason, despite the aforementioned information about ROSs in response to physical activity, there is no consensus of what the best post-workout recovery would be to minimize oxidative stress in the athletes' body $[6,9,10]$, especially because the physical exercises models and their evaluation methods have not been standardized, which makes a conclusive analysis difficult $[6,9,10]$. In this sense, the present study raised the hypothesis 
that using IBU during the recovery period of Paralympic Powerlifting athletes is beneficial for the parameters of sports performance, immunity maintenance and the reduction of oxidative stress.

In this regard, the objective of the present study was to analyze the effects of the use of ibuprofen on performance parameters, cell count and oxidative stress in national level Paralympic Powerlifting athletes in the period of resisted post-training recovery.

\section{Materials and Methods}

\subsection{Study Design}

The study design is shown in Figure 1. The study was carried out in three weeks, using the adapted bench press [20], with the first week being aimed at familiarization and the second and the third at the recovery method with the use of placebo (PLA) and Ibuprofen (IBU), the collections of the Peak Torque (PT), Rate of Torque Development (RTD), Fatigue Index (FI), Oxidative Stress Assessment through Thiobarbituric Acid Reactive Substances (TBARS) and Sulfidril Groups (SH), in addition to the blood indicators performed through the blood count and ammonia after training.

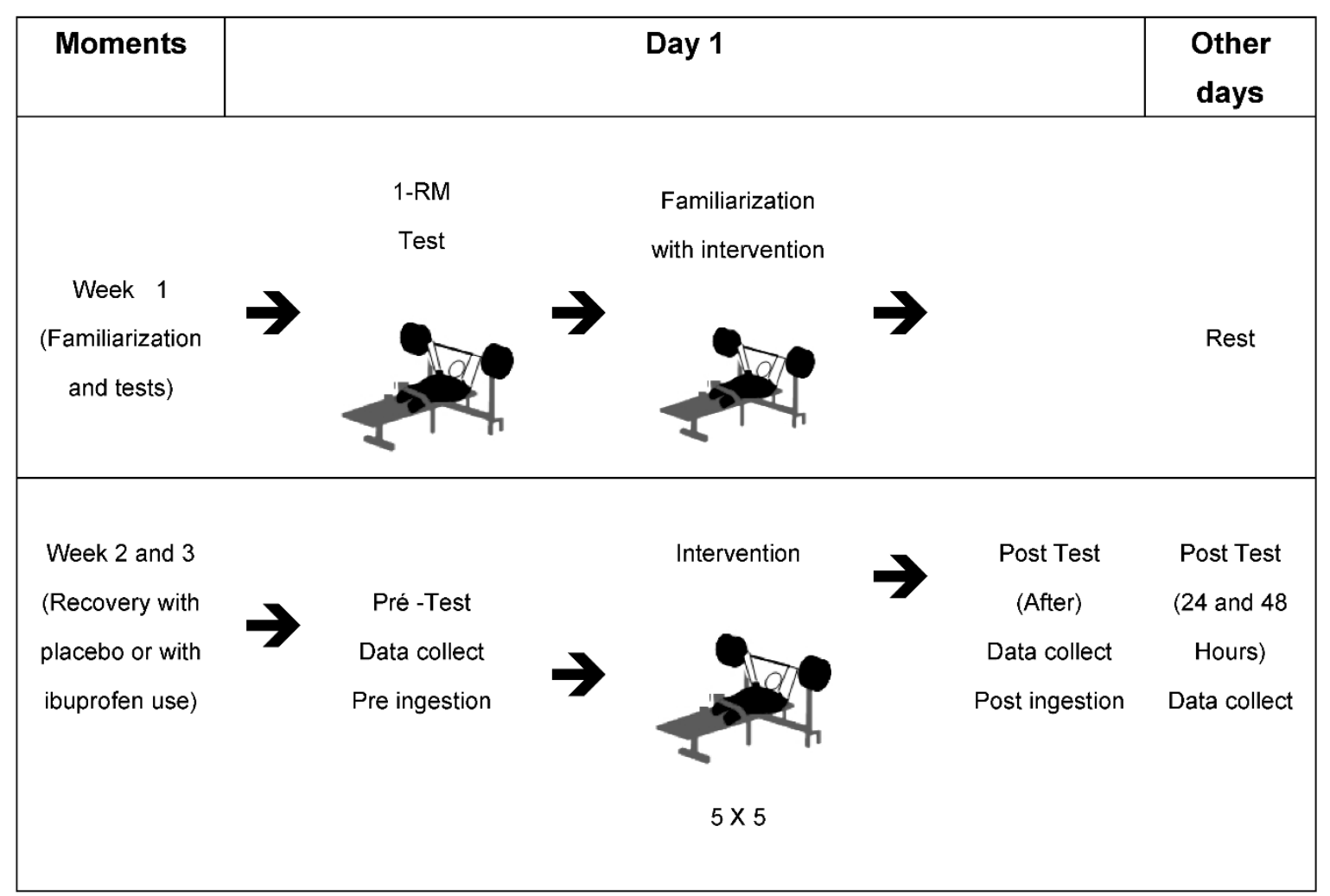

Figure 1. Experimental drawing. Weekly training schedule.

The order of the PLA or IBU conditions was determined randomly through a draw, considering $50 \%$ for each condition.

Week 1: familiarization; Week 2 and 3: recovery with the use of Ibuprofen or Placebo (week 2, 50\% PLA and 50\% IBU, changing in week 3). Pre-ingestion: $400 \mathrm{mg}$ Ibuprofen/Placebo ingestion 15 min before training; Intervention: training length ( $3 \mathrm{~h}$ ); Postingestion: $400 \mathrm{mg}$ Ibuprofen/Placebo ingestion $5 \mathrm{~h}$ after training $(5 \mathrm{~h})$; Data collection: measures of strength in the Adapted Bench Press (FI: Fatigue Index, RTD: Rate of Torque Development, PT: Peak Torque), Oxidative Stress, TBARS: Thiobarbituric Acid Reactive Substances; SH: Sulfhydryl groups. After training, Ammonia and CBC were evaluated. 1-RM: One Maximum Repetition. 
Collections were carried out between 9 a.m. and 12 p.m., according to the participants' availability. All assessments were carried out 30 min before the training started and immediately after, $24 \mathrm{~h}$ and $48 \mathrm{~h}$ after the training. The participants were evaluated for the rate of torque development, peak torque and fatigue index. The blood variables evaluated were the cell count of the immune system and markers of oxidative stress \{thiobarbituric acid (TBARS) and sulfhydryl groups $(\mathrm{SH})\}$ were performed before, after, two hours later, $24 \mathrm{~h}$ and $48 \mathrm{~h}$ after.

Before the intervention began, the athletes performed a previous warm-up for the upper limbs, using three exercises: (1) pulley elbow extension, (2) shoulders rotations with dumbbells, (3) shoulders abduction with dumbbells. Three sets of 10 to 20 maximum repetition (1-RM) were carried out; the warm-up lasted approximately $10 \mathrm{~min}[3,21]$. Then, a specific warm-up was performed on the bench press itself with $30 \%$ of 1-RM where: 10 slow repetitions (eccentric 3 -s $\times$ concentric 1 -s) and 10 rapid repetitions (eccentric 1 -s $\times$ concentric 1-s) were performed before the intervention started. It is noteworthy that during the specific warm-up, athletes received verbal encouragement to give their maximum performance $[3,21]$.

Subsequently, the athletes were submitted to an intervention of five sets of five maximum repetitions (5 repetitions with $80-90 \%$ of $1-\mathrm{RM}$ ). In the intervention, the traditional method was applied, using only fixed loads (invariable resistance). Two types of recovery were applied: one using the wheat flour placebo and the other using the IBU (400 mg) where both groups ingested the tablet 15 min before and $5 \mathrm{~h}$ after training.

\subsection{Sample}

The sample was entirely composed of male athletes [20]. Forty percent of the athletes had spinal cord injury below the eighth thoracic vertebra, 20\% had sequelae due to polio, $20 \%$ had a malformation of the lower limbs and $20 \%$ had disabilities due to brain injury. The athletes were of Brazilian nationality and competed on a national level with rankings in the top 10 of their respective categories. Exclusion criteria were adopted: (1) not participating in any phase of monitoring and data collection, (2) in the $24 \mathrm{~h}$ prior to the collection, strenuous exercise, (3) consumption of alcohol, caffeine, non-steroidal antiinflammatory drugs (including IBU), nutritional supplements (confirmed by interview), (4) be allergic to Ibuprofen, (5) having any muscle or joint injuries and/or reporting a change in arterial hypertension.

The sample size was determined a priori based on a previous study [1], which found an effect size of partial squared eta $\left(\eta^{2} p\right)=0.6$ for the analyses of the influence of ibuprofen on neuromuscular aspects in Paralympic Powerlifting athletes (in this case the variable was creatine kinase). Thus, the open-source $G^{*}$ Power software (Version 3.0; Berlin, Germany) was used in the statistical configuration for family tests " $\mathrm{F}$ " (ANOVA two way), considering an $\alpha<0.05$ and a $\beta=0.80$. In addition, two groups (placebo $\mathrm{x}$ ibuprofen) in four distinct measures (Before $\times$ After $\times$ After $24 \mathrm{Hs} \times$ After $48 \mathrm{Hs}$ ) were considered. Thus, a minimum sample size of six subjects was indicated for the present study, with the sample power estimated at 0.80 .

Table 1 shows the sample characterization.

Table 1. Sample characterization.

\begin{tabular}{lc}
\hline Variables & (Mean \pm Standard Deviation) \\
\hline$n$ & 10 \\
Age (years) & $27.13 \pm 5.57$ \\
Body Weight $(\mathrm{kg})$ & $79.25 \pm 25.51$ \\
Experience (years) & $2.99 \pm 0.51$ \\
1-RM/Bench press $(\mathrm{kg})$ & $137.13 \pm 30.53{ }^{*}$ \\
1-RM/Body Weight & $1.80 \pm 0.31{ }^{* *}$ \\
${ }^{*}$ All athletes with loads that keep them in the top 10 of their categories nationwide. ** Athletes with values above
\end{tabular}

1.4 in the Bench Press (1-RM/Body Weight) would be considered elite athletes, according to Ball \& Wedman, [22]. 


\subsection{Ethics}

The athletes participated in the study voluntarily and signed a free and informed consent term, in accordance with resolution 466/2012 of the National Research Ethics Commission-CONEP, of the National Health Council, following the ethical principles expressed in the Helsinki Declaration (1964, reformulated in 1975, 1983, 1989, 1996, 2000, 2008 and 2013), by the World Medical Association. In addition, the present clinical trial was previously registered (CAEE ID: 79909917.0.0000.55.46) and approved by the Human Research Ethics Committee of the Federal University of Sergipe (UFS), under Statement Number 2637882/2018.

\subsection{Body Mass Analysis}

Body mass was measured while sitting on a Micheletti Electronic Wheelchair Scale (Model Mic Wheelchair) of the digital electronic platform type (Micheletti ${ }^{\circledR}$, São Paulo, Brazil) with a maximum weight capacity of $500 \mathrm{~kg}$ (dimensions of $5.0 \mathrm{~cm}$ thickness, with a diameter of $102 \times 120 \mathrm{~cm}$ ).

\subsection{Maximum Training Load Analysis}

In order to determine the maximum training load, the 1-Repetition Maximum (1-RM) test was performed and, because the individuals evaluated were familiarized with the 1-RM test, they were not submitted to familiarization sessions. In the test, each subject started the attempts with a weight that could be lifted using maximum effort. Afterwards, weight increments were added until reaching the maximum load that could be lifted only once. If the practitioner was unable to perform a single repetition, 2.4 to $2.5 \%$ of the load used in the test were subtracted. The subjects rested $3-5 \mathrm{~min}$ between attempts $[3,22]$.

\subsection{Upper Limbs Muscle Strength}

To measure muscle strength, the Fatigue Index (FI), the Peak Torque (PT), and the Rate of Torque Development (RTD) were determined by a Chronojump load cell (Chronojump ${ }^{\circledR}$, BoscoSystem, Madrid, Spain), fixed on the Straight Bench Press, using Spider HMS Simond carabiners (Chamonix, France), with a breaking load of $21 \mathrm{KN}$, approved for climbing by the Union International des Associations d'Alpinisme (UIAA). A steel chain with a breaking load of $2300 \mathrm{~kg}$ was used to secure the load cell to the bench. The perpendicular distance between the load cell and the center of the joint was determined and used to calculate joint torques and fatigue index [21,23].

The isometric peak torque (PT) was measured by the maximum torque generated by the muscles of the upper limbs. PT was determined by the product of the peak isometric force, measured between the load cell cable fixation point and the adapted bench press, which was adjusted so that there was an angle close to $90^{\circ}$ at the elbow, at a $15 \mathrm{~cm}$ distance from the starting point (chest to bar), verified with a device for measuring the angular amplitude, Model FL6010 (Sanny ${ }^{\circledR}$, São Bernardo do Campo, Brazil). Participants were instructed to perform a single maximum movement until elbow extension (as fast as possible) and then relax, for PT evaluation.

As for the Fatigue Index (FI) assessment, the same exercise was performed and it was determined that the subjects maintained the maximum contraction for $5.0 \mathrm{~s}$, where the index was determined by dividing the initial PT in relation to the final PT, subtracted from one. $\mathrm{FI}=\{($ Maximum PT - Minimum PT $/$ Maximum Pt $) \times 100\}$. Thus, the results in Newton $(\mathrm{Nm})$ were conceived by the formula $\mathrm{Nm}=(\mathrm{M}) \times(\mathrm{C}) \times(\mathrm{H})$, where $\mathrm{M}=$ Body mass in $\mathrm{kg}, \mathrm{C}=9.80665, \mathrm{H}=$ Height of the bar in relation to the cell load $(0.45 \mathrm{~m})$, corresponding to the height that the equipment was fixed, adopting an angle of $90^{\circ}$ between the forearm and the arm. The Rate of Torque Development (RTD) was determined using the Peak Torque to time ratio until reaching the Peak Torque (RTD $=\Delta$ Peak Torque $/ \Delta$ Time), in $300 \mathrm{~ms}[21]$. 


\subsection{Blood Sample Collection}

Blood samples were collected in the antecubital vein of the forearm and immediately transferred to tubes with EDTA. Blood collection $(10 \mathrm{~mL})$ was performed by a health professional (two nursing technicians). The samples were placed in vacuum blood collection tubes and sent to the Clinical Laboratory of the University Hospital of the Federal University of Sergipe (Aracaju, Sergipe, Brazil), where biochemical analyzes were performed by a laboratory biochemist.

\subsection{Blood Cell and Leukocyte Count (HEMOGRAM)}

Cell Dyn Ruby Abbott-The Cell-Dyn Ruby is an automatic hematology analyzer and multiparameter. The machine uses three basic methods. (1) The optical method is used to obtain red blood cell, platelet and leukocyte global counts. A photosensitive detector measures light scattering. The detected pulse length is proportional to the particle size (leukocyte, erythrocyte or platelet), which enables the identification of the volume of each of the formed elements of the blood. (2) In Laser Flow Cytometry, a flow of particulate matter passes through the laser beam crossing at an angle of 90 degrees, dispersing the light to a photomultiplier, which generates pulses in the histograms by determining the size and granularity of cells. This analysis is used to perform global and differential counts of leukocytes in 5 parts (neutrophils, lymphocytes, monocytes, eosinophils and basophils). (3) Colorimetry is a method that utilizes a chemical reaction color change and the final absorbance reading reaction, and is used for hemoglobin. Full blood counts were performed using a five-part differential hematology analyzer (Beckman Coulter AcT 5 diff AL Hematology Analyzer, CA, USA). The hematology analyzer uses a sequential dilution system and a dual-focused flow fluid dynamics technology, employing the Coulter Principle of impedance to count and measure the size of the cells.

\subsection{Oxidative Stress}

For oxidative stress, the tubes were centrifuged $(3000 \times g$ for $10 \mathrm{~min})$, and the plasma and serum were then aliquoted and stored at $4{ }^{\circ} \mathrm{C}$ for further analysis. To prevent the loss of volatile compounds, plasma ammonia was immediately measured using a spectrophotometric assay (Randox ${ }^{\circledR}$, Crumlin, UK). The blood was centrifuged at $800 \times g$ for 15 min at $4{ }^{\circ} \mathrm{C}$ and the was serum stored at $-80^{\circ} \mathrm{C}$.

In the serum, oxidative stress markers were evaluated. Lipoperoxidation was determined by measuring substances reactive to thiobarbituric acid (TBARS), according to the method described by Lapenna et al. [24]. For TBARS, $200 \mu \mathrm{L}$ aliquots of the blood samples were added to a $400 \mu \mathrm{L}$ mixture formed by equal parts of $15 \%$ trichloroacetic acid (TCA), $0.25 \mathrm{~N} \mathrm{HCl}$ and $0.375 \% \mathrm{TBA}$, plus $2.5 \mathrm{mM}$ hydroxytoluene butylate (BHT) and $40 \mu \mathrm{L}$ of $8.1 \%$ sodium dodecyl sulfate (SDS), being heated for $30 \mathrm{~min}$ at $95{ }^{\circ} \mathrm{C}$ in an oven. The $\mathrm{pH}$ of the mixture was adjusted to 0.9 with concentrated $\mathrm{HCl}$. BHT was used to prevent lipid peroxidation during heating. After cooling to room temperature and adding $4 \mathrm{~mL}$ of butanol, the material was centrifuged at $800 \times g$ for $15 \mathrm{~min}$ at $\pm 4{ }^{\circ} \mathrm{C}$ and the absorbance of the supernatant was measured at $532 \mathrm{~nm}$. The molar extinction coefficient used was $1.54 \times 105 \mathrm{M}^{-1} \mathrm{~cm}^{-1}$ and the TBARS result was expressed in nmol Eq MDA/mL for the plasma samples.

The determination of sulfhydryl groups (SH) was carried out according to the methodology described by Faure and Lafond [25]. A $50 \mu \mathrm{L}$ aliquot of the plasma was mixed in $1 \mathrm{~mL}$ of Tris-EDTA buffer $(1 \mathrm{mM})$, and the first reading was taken at $412^{\circ}$ (A1 reading). After this reading, $20 \mu \mathrm{L}$ of $10 \mathrm{mM}$ 5,5'-dithiobis 2-nitrobenzoic acid (DTNB) diluted in methanol were added. A new reading was taken after $15 \mathrm{~min}$ at room temperature (A2 reading). The Blank (B) contained only DTNB and Tris-EDTA buffer. The final unit was expressed in $\mathrm{mM}$. The total sulfhydryl groups were calculated according to the molar absorption coefficient $=13,600 \mathrm{~cm}^{-1} \mathrm{M}^{-1}$ : $(\mathrm{A} 2-\mathrm{A} 1-\mathrm{B}) \times 1.57 \mathrm{mM}[25]$. 


\subsection{Post-Workout Recovery Using a Placebo}

The control group received two sugar capsules, with packages identical to the IBU, $15 \mathrm{~min}$ before and $5 \mathrm{~h}$ after the resistance training. The same protocol as the IBU was followed, as described below.

\subsection{Post-Workout Recovery Using Ibuprofen}

This study followed the protocol used by De Souza et al. [16] and Fraga et al. [1], which consisted of administering IBU $15 \mathrm{~min}$ before and $5 \mathrm{~h}$ after resistance training. The experimental group received two capsules of IBU ( $400 \mathrm{mg}$ ) adding up to a total of $800 \mathrm{mg}$. Both IBU and PLA were packaged in identical capsules and the experiment was doubleblind (i.e., participants and evaluators were unaware of what the capsules' substance was). Upon receiving the capsules, all volunteers were instructed on the ingestion procedures. Follow-up calls from the research team ensured compliance.

\subsection{Statistical Analysis}

The normality of the data was tested by the Shapiro Wilk test and the assumption was not denied. Descriptive statistics were used with measures of central tendency, mean $(\mathrm{X}) \pm$ Standard Deviation (SD). Comparisons with ammonia were performed using the paired Student's t test. For the t-test, an effect size (Cohen's " $d$ ") was considered, adopting values of low effect $(\leq 0.20)$, medium effect $(0.20$ to 0.80$)$, high effect $(0.80$ to 1.20$)$ and very high effect $(>1.20)$ [26-28]. For performance comparisons between time periods (Before $\times$ After $\times$ After $24 \mathrm{Hs} \times$ After $48 \mathrm{Hs}$ ), the assumptions were complicit for the use of the ANOVA test (Two Way). Point differences were verified by Bonferroni's Post Hoc. For ANOVA, the effect size was verified by the "partial squared eta" $(\eta 2 p)$, adopting values of low effect $(\leq 0.05)$, medium effect $(0.05$ to 0.25$)$, high effect ( 0.25 at 0.50$)$ and very high effect $(>0.50)$ [28]. All statistical treatment was performed using the computerized package Statistical Package for the Social Science (SPSS; version 22.0) considering that the level of significance adopted was $p<0.05$.

\section{Results}

It is noteworthy that, based on the effect size results of the present study, the calculation of the sampling power through the open-source software $G^{*}$ Power software (Version 3.0; Berlin, Germany) was performed, considering an $\alpha<0.05$ and a $\beta=0.80$. In this sense, the sample showed a power of $>0.80$ for the variables PT, FI, lymphocyte count, TBARS and $\mathrm{SH}$.

Figure 2 presents the data related to the isometric strength through the Peak Torque (PT), Rate of Torque Development (RTD) and Fatigue Index (FI).
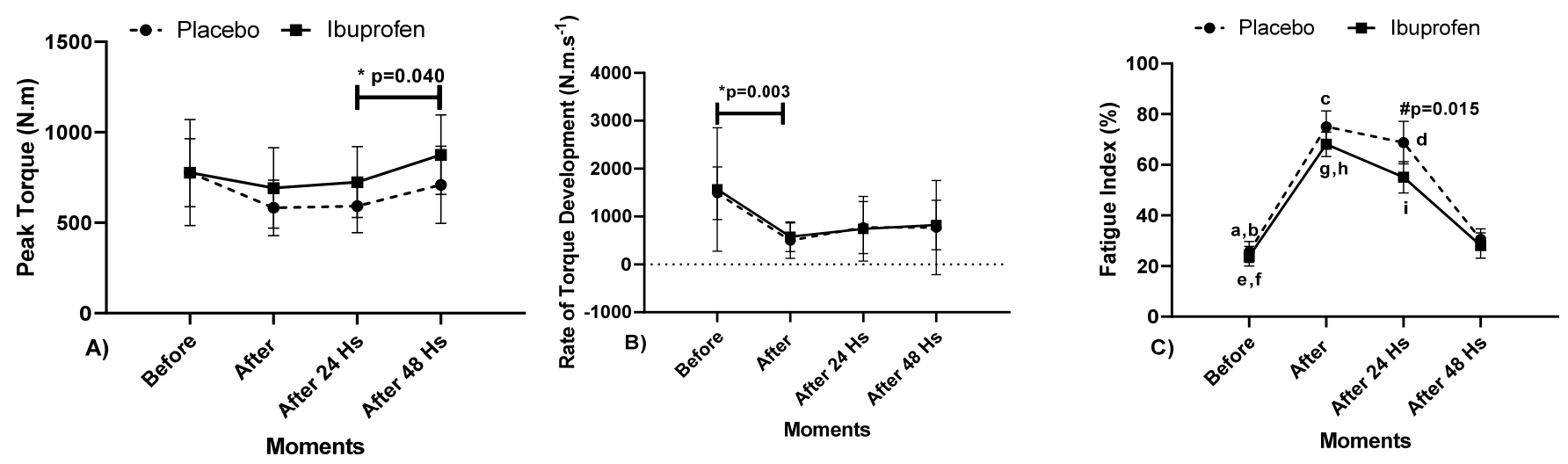

Figure 2. (A) Peak of Torque (PT), (B) Rate of Torque Development (RTD) e (C) Fatigue Index (FI) in diverse moments with Placebo (PLA) and Ibuprofen (IBU) used in recovery. Legend: "*”: Indicates IntraClass difference in (A,B); "a- $\mathrm{h}$ ": Indicates IntraClass differences in $(\mathbf{C})$ and "\#": Indicates InterClass difference $(\mathbf{C})(p<0.05)$. 
Regarding the results, the data presented point to: Figure $2 \mathrm{~A} \mathrm{PT}-$ " $*$ " Indicates a difference (IntraClass) in Ibuprofen (IBU) between the moments 24 and $48 \mathrm{~h}$ later ( $p=0.040$, $\eta 2 p=0.399$, high effect), in PLA there were no differences. Figure 2B) RTD_ “*” Indicates a difference (IntraClass) in Placebo (PLA) between the moments before and after $(p=0.003$, $\eta 2 p=0.542$, very high effect). Figure 2C FI- “\#” Indicates the difference between PLA and IBU (InterClass), at the moment $24 \mathrm{~h}$ later, $(p=0.015, \mathrm{\eta} 2 p=0.745$, very high effect). Regarding the supplement (IntraClass), in PLA— "a" Indicates a difference in the moments before and after; " $b$ " in the moments before and $24 \mathrm{~h}$ after; "c" in the moments after and after $48 \mathrm{~h}$ and " $\mathrm{d}$ " in the moments 24 and $48 \mathrm{~h}$ afterwards $(p<0.001)$. In the IBU supplement- " $\mathrm{e}$ " Indicates a difference between before and after; " $\mathrm{f}$ " in the moments before and $24 \mathrm{~h}$ after, " $\mathrm{g}$ " in the moments after and after $48 \mathrm{~h}$ and in the moments 24 and $48 \mathrm{~h}$ later $(p<0.001)$ and " $\mathrm{h}$ " in the moments after and $24 \mathrm{~h}$ after $(p=0.012)$. For PLA and IBU, $12 p=0.982$ (very high effect).

Table 2 shows the results of the blood count and blood variables, concerning to the changes in the cell counts of the volunteers' immune system when comparing the post-PLA and the post-IBU.

Table 2. Blood markers in the presence and the absence of Ibuprofen.

\begin{tabular}{lcccc}
\hline Variables & Placebo & Ibuprofen & $\boldsymbol{p}$ & Cohen's d \\
\hline CPR (mg/dL) & $1.80 \pm 1.47$ & $3.55 \pm 2.37$ & $0.031^{*}$ & $1.80 \mathrm{~d}$ \\
Urea (mg/dL) & $28.88 \pm 6.66$ & $24.38 \pm 6.74$ & 0.074 & $3.35 \mathrm{~d}$ \\
Uric acid (mg/dL) & $5.14 \pm 1.10$ & $5.50 \pm 1.21$ & 0.140 & $1.41 \mathrm{~d}$ \\
Leukocytes (mm $\left.{ }^{3}\right)$ & $7.41 \pm 1.80$ & $6.64 \pm 1.67$ & 0.415 & $2.08 \mathrm{~d}$ \\
Neutrophils (\%) & $3.72 \pm 1.22$ & $4.88 \pm 1.14$ & 0.151 & $4.66 \mathrm{~d}$ \\
Lymphocytes (\%) & $2.43 \pm 0.58$ & $3.48 \pm 0.78$ & $0.001 *$ & $4.36 \mathrm{~d}$ \\
Erythrocytes (million $\left./ \mathrm{mm}^{3}\right)$ & $5.06 \pm 0.39$ & $5.13 \pm 0.46$ & 0.221 & $0.64 \mathrm{~b}$ \\
Hemoglobin (g/mL) & $15.08 \pm 1.12$ & $15.00 \pm 1.43$ & 0.767 & $0.20 \mathrm{a}$ \\
Hematocrit $(\%)$ & $42.63 \pm 3.30$ & $43.95 \pm 4.00$ & $0.019 *$ & $1.31 \mathrm{~d}$ \\
MCV (U3) & $84.29 \pm 2.21$ & $85.67 \pm 3.36$ & 0.090 & $1.08 \mathrm{c}$ \\
MCH (UUG) & $29.79 \pm 0.52$ & $29.23 \pm 0.89$ & 0.123 & $1.42 \mathrm{~d}$ \\
MCHC (\%) & $35.36 \pm 0.94$ & $34.12 \pm 1.14$ & $0.007 *$ & $4.31 \mathrm{~d}$ \\
RDW (\%) & $10.24 \pm 3.35$ & $11.50 \pm 0.54$ & 0.305 & $0.45 \mathrm{~b}$
\end{tabular}

* $p \leq 0.05$ (ANOVA two way and Post Hoc de Bonferroni). "a" small effect $(\leq 0.20)$, " $\mathrm{b}^{\text {" medium effect }(0.20 \mathrm{a}}$ $0.80)$, "c" high effect $(0.80$ a 1.20) and "d" very high effect (>1.20). Legend: MCV: Mean Corpuscular Volume, MCHC: Mean Corpuscular Hemoglobin Concentration, RDW: Erythrocyte anisocytosis index.

The levels of C-Reactive Protein (CRP) increased $(1.80 \pm 1.47$ to $3.55 \pm 2.37 \mathrm{mg} / \mathrm{dL}$, $p=0.031$ ). There was no significant decrease in the total leukocyte count from $7.41 \pm 1.80$ to $6.64 \pm 1.67\left(\mathrm{~mm}^{3}\right)(p=0.415)$ and a raise in the percentage of neutrophils $3.72 \pm 1.22$ $(\%)$ for $4.88 \pm 1.14(\%)(p=0.151)$ did not suffer a statistical difference, the percentage of lymphocytes from $2.43 \pm 0.58$ to $3.48 \pm 0.78(\%)$ was increased $(p=0.001)$. All values remained within the reference values for cell counts for the adult population.

Figure 3 shows Oxidative Stress (TBARS and $\mathrm{SH}$ ) at different times with the use of a placebo (PLA) and Ibuprofen (IBU) at different times.

Regarding Oxidative Stress, the following differences were presented: Figure 3A TBARS, "\#” Difference between PLA and IBU after $48 \mathrm{~h}(p=0.010)$, "a" Difference in PLA between Before and $24 \mathrm{~h}$ after $(p=0.023)$, "B" Difference in PLA between 2 and $24 \mathrm{~h}$ after $(p<0.001)$, and " $c$ " Difference in PLA between 24 and $48 \mathrm{~h}$ after $(p=0.034), \mathrm{n} 2 p=0.173$ (InterClass, medium effect) and $\eta 2 p=0.479$ (Intra Group, high effect). Figure 3B SH, "a" Difference in PLA Before and $24 \mathrm{~h}$ after $(p=0.030)$, and " $\mathrm{b}$ " Difference in IBU Before and $2 \mathrm{~h}$ after $(p=0.001), \eta 2 p=0.484$ (IntraClass, high effect). 

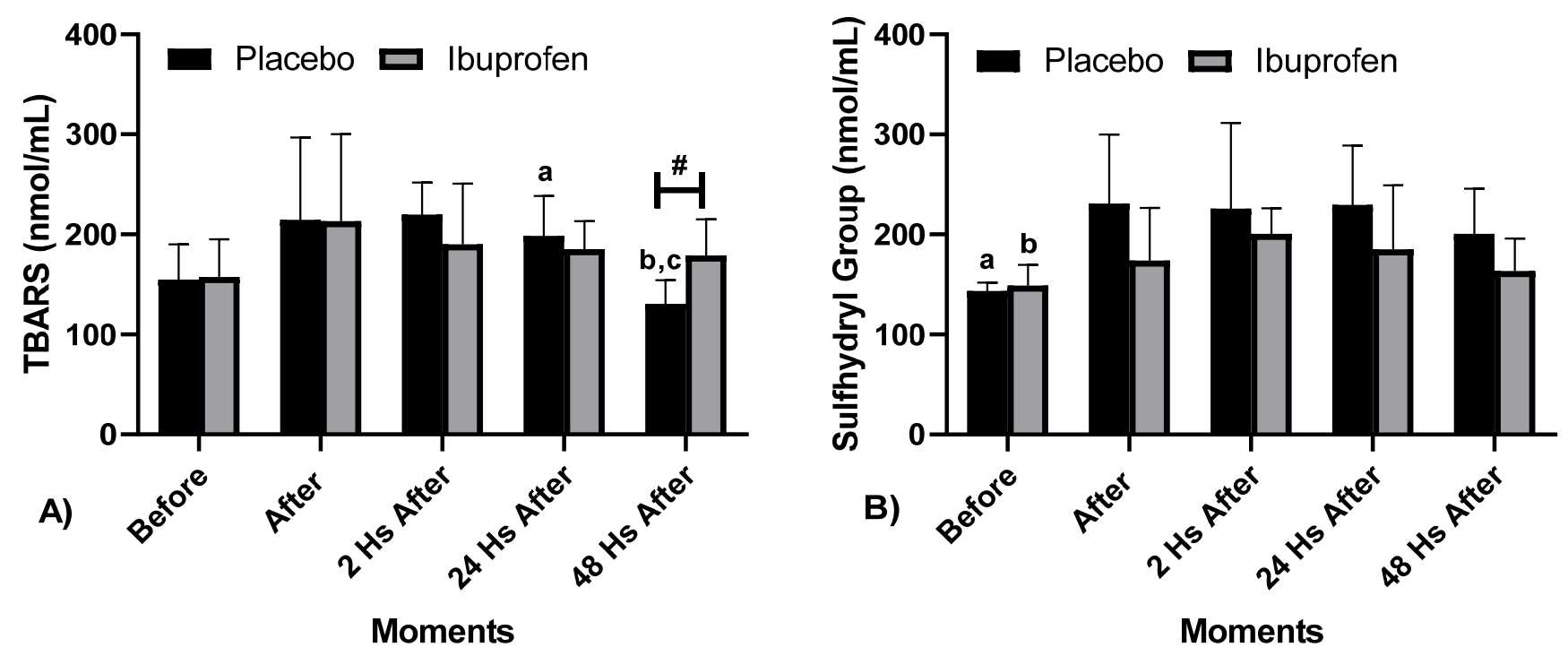

Figure 3. Oxidative Stress (A) Thiobarbituric Acid Reactive Substance (TBARS) e (B) Sulfhydrys Group (SH), at diverse moments with Placebo (PLA) and Ibuprofen (IBU) use at recovery. Legend: "a-c": Indicates IntraClass differences, and "\#": Indicates InterClass difference C) $(p<0.05)$.

\section{Discussion}

This study aimed to analyze the effect of IBU on resisted post-workout recovery in PP athletes, by biomechanical variables and through biochemical indicators for muscle damage in the blood. The results highlighted that the Peak Torque with the use of IBU between 24 e $48 \mathrm{~h}$ after presented a significant difference, which resulted in better athlete performance. When evaluating the RTD, there was a decrease in the rate before and after training in the recovery method with PLA, and there were no differences in the IBU. The Fatigue Index was higher in recovery with the use of PLA after training compared to the use of IBU afterwards.

The results after the use of the IBU contributed to an improvement in the maximum isometric strength in relation to the use of the IBU $48 \mathrm{~h}$ after the training and the PLA $24 \mathrm{~h}$ after. A significant difference was also found with the use of the IBU $48 \mathrm{~h}$ after and PLA after the training. Therefore, it can be noticed that there was a maintenance of muscle function in the recovery with the use of IBU in the adapted bench press in Paralympic Powerlifting athletes concerning the PLA. This result can also be seen in the study by De Souza et al. [16] who demonstrated to mitigate fatigue in the gastrocnemius muscle in competing male runners who used IBU. Thus, when evaluating the FIM, the participants found better performance in the squat jump after the race than the control group.

The fatigue index showed significant differences in the results at all times of recovery. The moment that showed the highest peak was right after training with the use of PLA in relation to the use of IBU and in $48 \mathrm{~h}$ the values started to normalize. This result demonstrates that the recovery with the use of the IBU decreased the Fatigue Index and at the same time increased the Maximum Isometric Strength.

The muscle's ability to generate strength can be decreased due to muscle fatigue, and damage the movement's motor control [29,30]. It is noteworthy that the cause of fatigue can be central (i.e., when it affects the nervous system linked to muscle contraction) or peripheral (i.e., inhibitions in the contraction mechanisms of skeletal muscles). Therefore, fatigue when installed can disorder the movement sequence of the muscle segment's movements [31], and the recovery becomes an important factor to observe [32].

In addition, this exercise protocol also demonstrated changes in the number of lymphocytes (immunological parameter). These data indicate that these extra blood cells were mobilized from the cell matrix because there was not enough time to produce new cells in the bone marrow [6]. The specific mechanisms by which leukocyte counts increase have been intensively discussed and some studies have suggested that exercise induces an 
increase in circulating stress hormones (growth hormone, epinephrine and norepinephrine) and that these hormones may play a role in the mobilization of white blood cells $[33,34]$. Increased production and the release of these hormones at the beginning of exercise can also stimulate the initial increase in the number of circulating leukocytes [35].

Recently, in a systematic review, Gonçalves et al. [6], exposed that many studies showed that intense physical activity increases the ROSs production in the human body. The results of this study do not show that intense physical activity, (represented here by the bench press) with five sets of five maximum repetitions ( $80-90 \%$ of $1-\mathrm{RM}$ ) was not capable to increase the ROSs production. In the present work, ROSs production was evaluated by the levels of TBARS and Sulfhydrys Group (SH). It is noteworthy that no other work had investigated the ROSs production using a similar protocol. Most studies use indirect methods to evaluate an increased ROSs production, for example, by measuring malonaldehyde (MDA), which is a marker of lipid peroxidation and reacts with thiobarbituric acid reactive substances (TBARS), signaling the existence of oxidative stress [36,37].

Barili et al. [38], found that the test on the treadmill was a sufficient stimulus to increase the peroxides production in elderly subjects. Wang et al. [39] investigated how the exercise intensity impacts redox status mediated by oxidation of Low-Density Lipoprotein (LDL) in monocytes. The aforementioned authors concluded the work by stating that high-intensity physical activity $\left(80 \% \mathrm{VO}_{2}\right.$ max) increases ROSs production. Miyazaki et al. [40] investigated whether the high-intensity training ( $80 \%$ HRmax), during twelve weeks, would alter the oxidative stress induced by exercise after an event until the fatigue, verifying that exercising until the fatigue increases the ability of the neutrophils to produce ROSs and the training decreases this ability.

Studies measuring oxidative stress between different exercise models, such as aerobic exercise to fatigue and isometric exercise, and even associations between systemic oxidative stress, exercise intolerance and skeletal muscle abnormalities in patients with cardiac problems [41]. Another study comparing before and after with three different exercise protocols with trained subjects showed an increase of oxidative stress after intervention compared to pre-exercise [42]. Conversely, physical inactivity can reduce the body's antioxidant systemic defense capacity [43].

It has also been shown that the immobilization of a leg for two weeks tends to induce the production of ROSs and impaired mitochondrial breathing capacity in the immobilized muscles [44]. Studies in humans indicate that exercise tends to be beneficial in the defense and prevention of oxidative stress, dependent on an inflammatory process $[45,46]$ since, during exercise, the inner membrane of the mitochondria interferes with ROSs, and the intensity or volume of exercise leads to an impact in the activity of free radical production that can interfere with the degrees of oxidative damage [47]. It seems that only a single session of acute exercise is able to increase the total antioxidant capacity [42]. Muscle damage tends to induce the build-up of neutrophils and cytokines, inducing oxidative stress [46]. On the other hand, researches indicate that chronic physical activities tend to increase adaptive and antioxidant defense systems [47,48].

Regarding the increase in free radicals, there is an indication that the antioxidant activity in the body tends not to decrease after intense chronic and acute exercises [46]. De Souza et al., [49] demonstrated lipid peroxidation in high intensity and long duration exercises in healthy individuals. Plasma MDA levels were measured before and after exercise until fatigue and did not undergo any significant changes. In the same direction, high intensity or exhaustive strength exercises tend to cause injuries and chronic fatigue. This would happen due to the imbalance between the production of reactive oxygen species (ROSs) and the endogenous antioxidant activity. Although ideal ROS production is important for muscle contraction, high ROSs concentrations tend to promote exerciseinduced fatigue [50,51].

Skeletal musculature is reported to produce greater amounts of superoxide anion during training [52]. However, improvements have been reported concerning the oxidative 
stress provided by strength training [53,54]. Nevertheless, a higher training volume tends not to alter oxidative stress markers [55]. In this direction, studies indicate that in trained weightlifting athletes, high-intensity strength training tends to increase oxidative stress and decrease the antioxidant capacity of these athletes [56], which tends to lead to unfavorable effects of exercise in relation to health. In training with loads above $70 \%$ of $1 \mathrm{RM}$, the oxidative stress markers did not change. In contrast, high-intensity strength training, such as the one in the study, tends to increase the level of oxidative markers, as well as tends to decrease the production of antioxidants in powerlifting athletes [56], despite moderate to high-intensity training tends to improve oxidative stress $[53,54]$. Thus, it appears that strength training tends to improve oxidative stress among athletes [57]. The use of antiinflammatory drugs, such as ibuprofen, tends to delay the anti-inflammatory response after exercise, helping the performance of powerlifting athletes [1], and this would explain the decrease in fatigue in the condition with ibuprofen use found in our study.

As is already widely discussed in the literature, high intensity or exhaustive physical exercise is recognized for increasing oxygen consumption resulting in a greater formation of reactive oxygen species (ROSs), greater susceptibility to muscle injuries and chronic fatigue [58]. In turn, non-steroidal anti-inflammatory agents (NSAIDs) became the most widely prescribed and used drugs worldwide $[59,60]$, the use of IBU Non-steroidal antiinflammatory drugs (NSAIDs) constitute one of the most consumed drug classes in the world. They have analgesic, antipyretic and anti-inflammatory effects that are used to treat acute pain arising from inflammation. Its effects occur through the reduction of the enzyme cyclooxygenase (COX), resulting in a decrease in precursors of prostaglandins and thromboxanes. The use of NSAIDs, when administered orally, is generally rapidly absorbed, it was found that the $400 \mathrm{mg}$ tablet of IBU showed a peak concentration of 20-40 $\mathrm{mg} / \mathrm{mL}$ in 1-2 $\mathrm{h}$ and decreasing to $5 \mathrm{mg} / \mathrm{mL}$ at the end of $6 \mathrm{~h}$ [61].

In this sense, the rapid absorption of IBU, which leads to rapid lowering of (MDA or TBARS) levels, occurs because it is subject to N-hydroxylation in the liver with the involvement of cytochrome P450 enzymes to form a toxic metabolite (NAPQI), which is rapidly inactivated by glutathione sulfhydryl (GSH) groups [62]. In large amounts of NAPQI, there is depletion of endogenous GSH in the liver and favors the binding of NAPQI with cellular biological macromolecules, such as proteins, nucleic acids and lipids, resulting in mitochondrial damage, endoplasmic reticulum stress and necrotic cell death. Then, in the toxicity phase, mitochondrial dysfunction increased oxidative stress occurs (damaged mitochondria lead to overproduction of reactive oxygen species (ROSs) $[63,64]$. As previously mentioned, the prophylactic use of IBU has a rapid absorption by the body, and as the levels of (MDA or TBARS) remain high as shown $48 \mathrm{~h}$ later. Finally, in studies carried out with animals that used ibuprofen, a cyclooxygenase inhibitor, the hematocrit and platelet counts were similar to those that did not receive ibuprofen [65].

As previously shown, the results of the present study agree with several other studies. However, it is necessary to emphasize that further research is still needed to recognize which model of physical activity really increases the production of ROSs without being neutralized by the antioxidant defense system, resulting in oxidative stress, which could cause damage to biomolecular structures.

Nevertheless, despite the important findings, the present study has limitations. The absence of monitoring food and quality of sleep of athletes during the recovery period made it impossible to control the intake of any food that would help to reduce oxidative stress and in the approach regarding sleep interference on oxidative stress.

\section{Conclusions}

It was concluded that the recovery with the use of Ibuprofen (IBU) presented a lower fatigue index and a lower decrease in strength when compared to the recovery with the placebo (PLA). There was also a reduction of muscle damage with the use of IBU compared to the recovery with PLA. This study demonstrated that, in the two forms of recovery, with 
PLA and with the use of the IBU after strength training, there was no protective effect of the anti-inflammatory on oxidative stress markers.

From the point of view of practical applications of the findings, the results indicate that the use of ibuprofen can be a good strategy in the recovery of athletes aiming for a new training session, when it is necessary to recover more effectively after a workout, and even for competitions, as it allows an improved recovery in relation to the recovery without the use of supplements.

Author Contributions: Conceptualization, F.J.A., G.S.F., M.G.-M. and A.C.M., methodology, F.J.A., G.S.F., J.L.S. and R.F.d.S., software, R.F.d.S.; and A.R.P.F., validation, E.B.N., A.B.-C., T.L.B.F. and P.F.d.A.-N., formal analysis, T.L.B.F., investigation, M.G.-M., A.C.M. and J.L.S., resources, A.R.P.F., and N.D.G.; data curation, A.L.D.-d.-D.; A.d.F.Z. and M.d.S.C.-S., writing-original draft preparation, M.M.-F., E.B.N., A.d.F.Z., A.B.-C., A.L.D.-d.-D. And B.G.d.A.T.C.; writing-review and editing, P.F.d.A.-N., N.D.G., M.d.S.C.-S., B.G.d.A.T.C. and F.M.C., visualization, M.M.-F., E.M.-C., supervision, F.M.C., project administration, F.M.C.; funding acquisition, E.M.-C. All authors have read and agreed to the published version of the manuscript.

Funding: This research received no external funding. Nuno Domingos Garrido was funded by FCT—Fundação Portuguesa para a Ciência e Tecnologia (UID04045/2020).

Institutional Review Board Statement: The study was conducted according to the guidelines of the Declaration of Helsinki, and approved by the Institutional Review Board and approved by the Human Research Ethics Committee of the Federal University of Sergipe (UFS), under Statement Number 2637882/2018.

Informed Consent Statement: Informed consent was obtained from all subjects involved in the study.

Data Availability Statement: The data that support this study can be obtained from the address: https://www.ufs.br/Department\%20of\%20Physical\%20Education, accessed on 12 July 2021.

Conflicts of Interest: The authors declare no conflict of interest.

\section{References}

1. Fraga, G.S.; Aidar, F.J; Matos, D.G.; Marçal, A.C.; Santos, J.L.; Souza, R.F.; Carneiro, A.L.; Vasconcelos, A.B.; Da Silva-Grigoletto, M.E.; Tillaar, R.V.D.; et al. Effects of Ibuprofen Intake in Muscle Damage, Body Temperature and Muscle Power in Paralympic Powerlifting Athletes. Int. J. Environ. Res. Public Health 2020, 17, 5157. [CrossRef]

2. Hecksteden, A.; Skorski, S.; Schwindling, S.; Hammes, D.; Pfeiffer, M.; Kellmann, M.; Ferrauti, A.; Meyer, T. Blood-Borne Markers of Fatigue in Competitive Athletes-Results from Simulated Training Camps. PLoS ONE 2016, 11, e148810. [CrossRef] [PubMed]

3. Sampaio, C.R.S.F.; Aidar, FJ.; Ferreira, A.R.P.; Santos, J.L.D.; Marçal, A.C.; Matos, D.G.; Souza, R.F.; Moreira, O.C.; Guerra, I.; Fernandes Filho, J.; et al. Can Creatine Supplementation Interfere with Muscle Strength and Fatigue in Brazilian National Level Paralympic Powerlifting? Nutrientes 2020, 12, 2492. [CrossRef] [PubMed]

4. Bessa, A.L.; Oliveira, V.N.; Agostini, G.G.; Oliveira, R.J.; Oliveira, A.C.; White, G.E.; Wells, G.D.; Teixeira, D.N.; Espindola, F.S. Exercise Intensity and Recovery. J. Strength Cond. Res. 2016, 30, 311-319. [CrossRef]

5. Nunes-Silva, A.; Bernardes, P.T.T.; Rezende, B.M.; Lopes, F.; Gomes, E.C.; Marques, P.E.; Lima, P.M.A.; Coimbra, C.C.; Menezes, G.B.; Teixeira, M.M.; et al. Treadmill Exercise Induces Neutrophil Recruitment into Muscle Tissue in a Reactive Oxygen Species-Dependent Manner. An Intravital Microscopy Study. PLoS ONE 2014, 9, e96464. [CrossRef]

6. Gonçalves, C.A.M.; Dantas, P.M.S.; Dos Santos, I.K.; Dantas, M.P.; Da Silva, D.C.P.; Cabral, B.G.D.A.T.; Guerra, R.O.; Júnior, G.B.C. Effect of Acute and Chronic Aerobic Exercise on Immunological Markers: A Systematic Review. Front. Physiol. 2020, 10, 1602. [CrossRef]

7. Macedo, N.C.D.; Iessi, I.L.; Gallego, F.Q.; Netto, A.O.; Sinzato, Y.K.; Volpato, G.T.; Zambrano, E.; Damasceno, D.C. Swimming Program on Mildly Diabetic Rats in Pregnancy. Reprod. Sci. 2021, 28, 2223-2235. [CrossRef]

8. Yang, D.K.; Lee, S.J.; Adam, G.O.; Kim, S.-J. Aralia continentalis kitagawa Extract Attenuates the Fatigue Induced by Exhaustive Exercise through Inhibition of Oxidative Stress. Antioxidants 2020, 9, 379. [CrossRef]

9. Speer, H.; D'Cunha, N.M.; Alexopoulos, N.I.; McKune, A.J.; Naumovski, N. Anthocyanins and Human Health-A Focus on Oxidative Stress, Inflammation and Disease. Antioxidants 2020, 9, 366. [CrossRef] [PubMed]

10. Varamenti, E.; Nikolovski, Z.; Elgingo, M.I.; Jamurtas, A.Z.; Cardinale, M. Training-induced variations in haematological and bio-chemical variables in adolescent athletes of arab origin throughout an entire athletic season. J. Hum. Kinet. 2018, 64, 123-135. [CrossRef]

11. Ammar, A.; Turki, M.; Hammouda, O.; Chtourou, H.; Trabelsi, K.; Bouaziz, M.; Abdelkarim, O.; Hoekelmann, A.; Ayadi, F.; Souissi, N.; et al. Effects of Pomegranate Juice Supplementation on Oxidative Stress Biomarkers Following Weightlifting Exercise. Nutritients 2017, 9, 819. [CrossRef] [PubMed] 
12. Ammar, A.; Chtourou, H.; Souissi, N. Effect of Time-of-Day on Biochemical Markers in Response to Physical Exercise. J. Strength Cond. Res. 2017, 31, 272-282. [CrossRef] [PubMed]

13. Ammar, A.; Chtourou, H.; Hammouda, O.; Turki, M.; Ayedi, F.; Kallel, C.; Abdelkarim, O.; Hoekelmann, A.; Souissi, N. Relationship between biomarkers of muscle damage and redox status in response to a weightlifting training session: Effect of time-of-day. Acta Physiol. Hung. 2016, 103, 243-261. [CrossRef] [PubMed]

14. Finaud, J.; Lac, G.; Filaire, E. Oxidative stress: Relationship with exercise and training. Sports Med. 2006, 36, 327-358. [CrossRef] [PubMed]

15. Ammar, A.; Chtourou, H.; Hammouda, O.; Trabelsi, K.; Chiboub, J.; Turki, M.; Abdelkarim, O.; El Abed, K.; ben Ali, M.; Hoekelmann, A.; et al. Acute and delayed responses of C-reactive protein, malondialdehyde and antioxidant markers after resistance training session in elite weightlifters: Effect of time of day. Chronobiol. Int. 2015, 32, 1211-1222. [CrossRef]

16. De Souza, R.F.; de Matos, D.G.; Ferreira, A.R.P.; Chilibeck, P.; Barros, N.D.A.; Oliveira, A.S.; Cercato, L.M.; da Silva, D.S.; Aidar, F.J. Effect of Ibuprofen on Muscle, Hematological and Renal Function, Hydric Balance, Pain, and Performance During Intense Long-Distance Running. J. Strength Cond. Res. 2020, 34, 2076-2083. [CrossRef]

17. Mishra, D.K.; Fridén, J.; Schmitz, M.C.; Lieber, R.L. Anti-inflammatory medication after muscle injury. A treatment resulting in short-term improvement but subsequent loss of muscle function. J. Bone Jt. Surg. Am. 1995, 77, 1510-1519. [CrossRef]

18. Bondesen, B.A.; Mills, S.T.; Kegley, K.M.; Pavlath, G.K. The COX-2 pathway is essential during early stages of skeletal muscle re-generation. Am. J. Physiol. Cell Physiol. 2004, 56, C475-C483. [CrossRef]

19. Bondesen, B.A.; Mills, S.T.; Pavlath, G.K. The COX-2 pathway regulates growth of atrophied muscle via multiple mechanisms. Am. J. Physiol. Cell Physiol. 2006, 290, C1651-C1659. [CrossRef]

20. International Paralympic Committee (IPC). World Para Powerlifiting. Rules \& Regulations. Available online: https: / / www.paralympic.org/sites/default/files/document/180215210800620_World\%2BPara\%2BPowerlifting\%2BRules\%2Band\% 2BRegulations_Feb\%2B2018_0.pdf (accessed on 13 October 2020).

21. Resende, M.; Resende, R.V.; Reis, G.; Barros, L.; Bezerra, M.; Matos, D.; Marçal, A.; Almeida-Neto, P.; Cabral, B.; Neiva, H.; et al. The Influence of Warm-Up on Body Temperature and Strength Performance in Brazilian National-Level Paralympic Powerlifting Athletes. Medicina 2020, 56, 538. [CrossRef]

22. Ball, R.; Weidman, D. Analysis of USA Powerlifting Federation Data From 1 January 2012-11 June 2016. J. Strength Cond. Res. 2018, 32, 1843-1851. [CrossRef]

23. Souza, R.F.; Nogueira, A.C.; Ferreira, A.R.P.; Matos, D.G.; Oliveira, L.S.L.; Zanona, A.F.; Aidar, F.J. Analysis of muscle recovery time after acute stretching at peak torque of the hamstring muscles. Med. Dello Sport 2019, 72, 171-180.

24. Lapenna, D.; Ciofani, G.; Pierdomenico, S.D.; Giamberardino, M.A.; Cuccurullo, F. Reaction conditions affecting the relationship between thiobarbituric acid reactivity and lipid peroxides in human plasma. Free Radic. Biol. Med. 2001, 31, 331-335. [CrossRef]

25. Faure, P.; Lafond, J.L. Measurement of plasma sulfhydryl and carbonyl groups as a possible indicator of protein oxidation. In Analysis of Free Radicals in Biological Systems; Favier, A.E., Cadet, J., Kalyanaraman, B., Fontecave, M., Pierre, J.L., Eds.; Birkhäuser Verlag: Basel, Switzerland, 1995; pp. 237-248.

26. Lakens, D. Calculating and reporting effect sizes to facilitate cumulative science: A practical primer for t-tests and ANOVAs. Front. Psychol. 2013, 4, 863. [CrossRef]

27. Lakens, D. Equivalence tests: A practical primer for t tests, correlations, and meta-analyses. Soc. Psychol. Personal. Sci. 2017, 8, 355-362. [CrossRef] [PubMed]

28. Cohen, J. Statistics a power primer. Psychol. Bull. 1992, 112, 155-159. [CrossRef] [PubMed]

29. Elshafei, M.; Shihab, E. Towards Detecting Biceps Muscle Fatigue in Gym Activity Using Wearables. Sensors 2021, 21, 759. [CrossRef]

30. Mushtaq, W.; Hamdani, N.; Noohu, M.M.; Raghavan, S. Effect of Modified Constrain Induced Movement Therapy on Fatigue and Motor Performance in Sub Acute Stroke. J. Stroke Cerebrovasc. Dis. 2020, 29, 105378. [CrossRef] [PubMed]

31. Kerhervé, H.A.; Stewart, D.G.; McLellan, C.; Lovell, D. Fatigue Indices and Perceived Exertion Highlight Ergometer Specificity for Repeated Sprint Ability Testing. Front. Sports Act. Living 2020, 2, 45. [CrossRef] [PubMed]

32. Chen, C.-Y.; Chou, W.-Y.; Ko, J.-Y.; Lee, M.S.; Wu, R.-W. Early Recovery of Exercise-Related Muscular Injury by HBOT. BioMed Res. Int. 2019, 2019, 1-10. [CrossRef] [PubMed]

33. Stolk, R.F.; Van Der Pasch, E.; Naumann, F.; Schouwstra, J.; Bressers, S.; Van Herwaarden, A.E.; Gerretsen, J.; Schambergen, R.; Ruth, M.M.; Van Der Hoeven, J.G.; et al. Norepinephrine Dysregulates the Immune Response and Compromises Host Defense during Sepsis. Am. J. Respir. Crit. Care Med. 2020, 202, 830-842. [CrossRef]

34. Basile, U.; Bruno, C.; Napodano, C.; Vergani, E.; Pocino, K.; Brunetti, A.; Gulli, F.; Santini, S.A.; Mancini, A. Plasmatic free light chains as inflammatory marker in insulin resistance: Comparison of metabolic syndrome with adult growth hormone deficiency. BioFactors 2018, 44, 480-484. [CrossRef] [PubMed]

35. Moro, T.; Tinsley, G.; Longo, G.; Grigoletto, D.; Bianco, A.; Ferraris, C.; Guglielmetti, M.; Veneto, A.; Tagliabue, A.; Marcolin, G.; et al. Time-restricted eating effects on performance, immune function, and body composition in elite cyclists: A randomized controlled trial. J. Int. Soc. Sports Nutr. 2020, 17, 1-11. [CrossRef] [PubMed]

36. Barbouti, A.; Vasileiou, P.V.S.; Evangelou, K.; Vlasis, K.G.; Papoudou-Bai, A.; Gorgoulis, V.G.; Kanavaros, P. Implications of Oxidative Stress and Cellular Senescence in Age-Related Thymus Involution. Oxid. Med. Cell. Longev. 2020, $2020,7986071$. [CrossRef] [PubMed] 
37. Sun, W.; Wang, Z.; Sun, M.; Huang, W.; Wang, Y.; Wang, Y. Aloin antagonizes stimulated ischemia/reperfusion-induced damage and inflammatory response in cardiomyocytes by activating the Nrf2/HO-1 defense pathway. Cell Tissue Res. 2021, 384, 735-744. [CrossRef] [PubMed]

38. Barili, A.; Corralo, V.D.S.; Cardoso, A.M.; Mânica, A.; Bonadiman, B.D.S.R.; Bagatini, M.D.; Da Silva-Grigoletto, M.E.; De Oliveira, G.G.; De Sá, C.A. Acute responses of hemodynamic and oxidative stress parameters to aerobic exercise with blood flow restriction in hypertensive elderly women. Mol. Biol. Rep. 2018, 45, 1099-1109. [CrossRef] [PubMed]

39. Wang, J.-S.; Lee, T.; Chow, S.-E. Role of exercise intensities in oxidized low-density lipoprotein-mediated redox status of monocyte in men. J. Appl. Physiol. 2006, 101, 740-744. [CrossRef] [PubMed]

40. Miyazaki, H.; Oh-Ishi, S.; Ookawara, T.; Kizaki, T.; Toshinai, K.; Ha, S.; Haga, S.; Ji, L.L.; Ohno, H. Strenuous endurance training in humans reduces oxidative stress following exhausting exercise. Eur. J. Appl. Physiol. 2001, 84, 1-6. [CrossRef]

41. Yokota, T.; Kinugawa, S.; Hirabayashi, K.; Yamato, M.; Takada, S.; Suga, T.; Nakano, I.; Fukushima, A.; Matsushima, S.; Okita, K.; et al. Systemic oxidative stress is associated with lower aerobic capacity and impaired skeletal muscle energy metabolism in heart failure patients. Sci. Rep. 2021, 11, 1-8. [CrossRef]

42. Souza, A.V.; Giolo, J.S.; Teixeira, R.R.; Vilela, D.D.; Peixoto, L.G.; Justino, A.B.; Caixeta, D.C.; Puga, G.M.; Espindola, F.S. Salivary and plas-matic antioxidant profile following continuous, resistance, and high-intensity interval exercise: Preliminary study. Oxid. Med. Cell. Longev. 2019, 2019, 5425021. [CrossRef]

43. Bouzid, M.A.; Hammouda, O.; Matran, R.; Robin, S.; Fabre, C. Influence of physical fitness on antioxidant activity and malondialdehyde level in healthy older adults. Appl. Physiol. Nutr. Metab. 2015, 40, 582-589. [CrossRef]

44. Gram, M.; Vigelsø, A.; Yokota, T.; Helge, J.W.; Dela, F.; Hey-Mogensen, M. Skeletal muscle mitochondrial H2O2 emission increases with immobilization and decreases after aerobic training in young and older men. J. Physiol. 2015, 593, 4011-4027. [CrossRef]

45. Koubaa, A.; Triki, M.; Trabelsi, H.; Baati, H.; Sahnoun, Z.; Hakim, A. The Effect of a 12-Week Moderate Intensity Interval Training Program on the Antioxidant Defense Capability and Lipid Profile in Men Smoking Cigarettes or Hookah: A Cohort Study. Sci. World J. 2015, 2015, 1-9. [CrossRef]

46. Nobari, H.; Nejad, H.; Kargarfard, M.; Mohseni, S.; Suzuki, K.; Adsuar, J.C.; Pérez-Gómez, J. The Effect of Acute Intense Exercise on Activity of Antioxidant Enzymes in Smokers and Non-Smokers. Biomolecules 2021, 11, 171. [CrossRef]

47. Pingitore, A.; Lima, G.P.P.; Mastorci, F.; Quinones, A.; Iervasi, G.; Vassalle, C. Exercise and oxidative stress: Potential effects of anti-oxidant dietary strategies in sports. Nutrition 2015, 31, 916-922. [CrossRef]

48. Bogdanis, G.; Stavrinou, P.; Fatouros, I.; Philippou, A.; Chatzinikolaou, A.; Draganidis, D.; Ermidis, G.; Maridaki, M. Short-term high-intensity interval exercise training attenuates oxidative stress responses and improves antioxidant status in healthy hu-mans. Food Chem. Toxicol. 2013, 61, 171-177. [CrossRef]

49. De Souza, R.F.; Augusto, R.L.; De Moraes, S.R.A.; De Souza, F.B.; Gonçalves, L.V.D.P.; Pereira, D.D.; Moreno, G.M.M.; De Souza, F.M.A.; Andrade-Da-Costa, B.L.D.S. Ultra-Endurance Associated with Moderate Exercise in Rats Induces Cerebellar Oxidative Stress and Impairs Reactive GFAP Isoform Profile. Front. Mol. Neurosci. 2020, 13, 157. [CrossRef]

50. De Araújo, S.S.; Aidar, F.J.; De Matos, D.G.; Santos, J.L.; Souza, L.M.V.; Silva, A.N.; Marçal, A.C.; Mourão, D.M.; Júnior, A.L.; Durães, G.M.; et al. Does Croton Argyrophyllus Extract Has an Effect on Muscle Damage and Lipid Peroxidation in Rats Submitted to High Intensity Strength Exercise? Int. J. Environ. Res. Public Health 2019, 16, 4237. [CrossRef] [PubMed]

51. Korivi, M.; Chen, C.-T.; Yu, S.-H.; Ye, W.; Cheng, I.-S.; Chang, J.-S.; Kuo, C.-H.; Hou, C.-W. Seaweed Supplementation Enhances Maximal Muscular Strength and Attenuates Resistance Exercise-Induced Oxidative Stress in Rats. Evid. Based Complement. Altern. Med. 2019, 2019, 3528932-9. [CrossRef] [PubMed]

52. Mastaloudis, A.; Yu, T.-W.; O’Donnell, R.P.; Frei, B.; Dashwood, R.H.; Traber, M.G. Endurance exercise results in DNA damage as detected by the comet assay. Free Radic. Biol. Med. 2004, 36, 966-975. [CrossRef] [PubMed]

53. Azizbeigi, K.; Azarbayjani, M.A.; Atashak, S.; Stannard, S.R. Effect of Moderate and High Resistance Training Intensity on Indices of Inflammatory and Oxidative Stress. Res. Sports Med. 2015, 23, 73-87. [CrossRef]

54. Ryrsø, C.K.; Thaning, P.; Siebenmann, C.; Lundby, C.; Lange, P.; Pedersen, B.K.; Hellsten, Y.; Iepsen, U.W. Effect of endurance versus resistance training on local muscle and systemic inflammation and oxidative stress in COPD. Scand. J. Med. Sci. Sports 2018, 28, 2339-2348. [CrossRef]

55. Koozehchian, M.S.; Daneshfar, A.; Fallah, E.; Agha-Alinejad, H.; Samadi, M.; Kaviani, M.; B., M.K.; Jung, Y.P.; Sablouei, M.H.; Moradi, N.; et al. Effects of nine weeks L-Carnitine supplementation on exercise performance, anaerobic power, and exercise-induced oxidative stress in resistance-trained males. J. Exerc. Nutr. Biochem. 2018, 22, 7-19. [CrossRef]

56. Jürgenson, J.; Serg, M.; Kampus, P.; Kals, J.; Zagura, M.; Viru, M.; Zilmer, K.; Zilmer, M.; Eha, J.; Unt, E. Oxidative Stress Parameters and Its Associations with Arterial Stiffness in Competitive Powerlifting Athletes After 12-Week Supervised Strength Training. J. Strength Cond. Res. 2019, 33, 1816-1822. [CrossRef]

57. Prasertsri, P.; Boonla, O. Upper and lower limb resistance training program versus high-intensity interval training on oxidative stress markers in university athletes. J. Exerc. Rehabil. 2021, 17, 198-206. [CrossRef] [PubMed]

58. Alves, N.F.; Porpino, S.K.; Monteiro, M.M.; Gomes, E.; Braga, V.A. Coconut oil supplementation and physical exercise improves baroreflex sensitivity and oxidative stress in hypertensive rats. Appl. Physiol. Nutr. Metab. 2015, 40, 393-400. [CrossRef] [PubMed]

59. Lima, F.D.; Stamm, D.N.; Della Pace, I.D.; Ribeiro, L.R.; Rambo, L.M.; Bresciani, G.; Ferreira, J.; Rossato, M.F.; Silva, M.A.; Pereira, M.E.; et al. Ibuprofen intake increases exercise time to exhaustion: A possible role for pre-venting exercise-induced fatigue. Scand. J. Med. Sci. Sports 2016, 26, 1160-1170. [CrossRef] 
60. McAnulty, S.R.; Owens, J.T.; McAnulty, L.S.; Nieman, D.C.; Morrow, J.D.; Dumke, C.L.; Milne, G.L. Ibuprofen use during extreme exercise: Effects on oxidative stress and PGE2. Med. Sci. Sports Exerc. 2007, 39, 1075-1079. [CrossRef] [PubMed]

61. López-Durán, J.L.; Frías-Iniesta, J. Drug synergism in analgesia treated with ibuprofen and codeine. SEMERGEN-Med. Fam. 2014, 38, 24-32. [CrossRef]

62. Trappe, T.A.; White, F.; Lambert, C.P.; Cesar, D.; Hellerstein, M.; Evans, W.J. Effect of ibuprofen and acetaminophen on post exercise muscle protein synthesis. Am. J. Physiol. 2002, 282, E551-E556.

63. Trappe, T.A.; Fluckey, J.D.; White, F.; Lambert, C.P.; Evans, W.J. Skeletal Muscle PGF2 $\alpha$ and PGE2 in Response to Eccentric Resistance Exercise: Influence of Ibuprofen and Acetaminophen. J. Clin. Endocrinol. Metab. 2001, 86, 5067-5070. [CrossRef] [PubMed]

64. Peterson, J.; Trappe, T.A.; Mylona, E.; White, F.; Lambert, C.P.; Evans, W.J.; Pizza, F.X. Ibuprofen and Acetaminophen: Effect on Muscle Inflammation after Eccentric Exercise. Med. Sci. Sports Exerc. 2003, 35, 892-896. [CrossRef] [PubMed]

65. Almqvist, P.M.; Ekström, B.; Kuenzig, M.; Haglund, U.; Schwartz, S.I. Increased survival of endotoxin-injected dogs treated with methylprednisolone, naloxone, and ibuprofen. Circ. Shock 1984, 14, 129-136. [PubMed] 